\title{
Influence of profile deck sheet in composite slab system
}

\author{
Jagadeesan $R^{1, *}$, Preetha $V^{2}$, Vignesh P.S ${ }^{3}$,Senthilkumar $V^{4}$ \\ ${ }^{1}$ Assistant Professor, Department of Civil Engineering, K.S Rangasamy college of Technology, Thiruchengode. \\ ${ }^{2}$ Assistant Professor (Senior grade), Department of Civil Engineering, Bannari Amman institute of technology, \\ Sathyamangalam.
}

${ }^{3} P G$ student, Department of civil, Bannari Amman institute of technology, Sathyamangalam.

${ }^{4}$ Associate Professor, Department of civil, Bannari Amman institute of technology, Sathyamangalam.

*Corresponding Author E-mail: jagadeesan.civil84@gmail.com

Doi: https://doi.org/10.34256/irjmtcon71

\begin{abstract}
Composite structures play a vital role in construction sector due to rapid completion of the projects. In composite structures, Plates are mostly used as a structural element for effective replacement of steel reinforcement. Normally the composite floor deck system involves a profile deck sheet as a bottom layer of slab system to take care of the tensile strength of the element. Concrete is poured over a deck sheet and with minimum reinforcement to take care of shrinkage stresses. Profile deck sheet plays a dual role as tensile reinforcement when concrete hardens and act as a temporary shuttering during fresh concreting. The main objective of this paper is to determine the vibration characteristics of profile deck sheet for various shapes of profile as composite slab system. Modal analysis is a technique in which vibration studies can be determined for various profile shapes by involving parameters such as mode shape, natural frequency, plate stresses and deformation by using finite element analysis.
\end{abstract}

Keywords: Profile deck sheet, modal analysis, vibration studies, Natural Frequency, Mode Shape.

\section{INTRODUCTION}

The widespread popularity of steel in multi-storey building construction is in part due to the use of composite floors. Steel concrete composite floor deck consists of concrete cast on top of cold-formed profiled steel sheets. During the construction stage, steel deck used in composite floor slabs is the formwork for the placement of concrete and a safe working platform for staging of equipment and materials. The steel deck allows work to progress to new floors before the concrete has been cast or reached full strength. Onto the deck sheet lightweight or normal weight concrete is poured to make up the composite system. They utilize the strengths of both materials to create a structural system with numerous advantages in the construction and service load stages. Composite floors with profiled decking consist of the profiled decking, shear connectors, reinforcement for shrinkage and temperature stresses as shown in figure: 1 . At the ends, the decks are supported generally by steel beam. The connection between floor and beam is made up with welded studs or any other type of local connection. The integral composite action between the steel deck and concrete is necessary to establish, which resist horizontal shear at the steel concrete interface and thereby and preventing vertical separation. For that either embossment are provided or dovetail shape of the profile is made. The use of profiled steel sheeting undoubtedly speeds up construction. It is also often used with lightweight concrete to reduce the dead load due to floor 
construction. The profile deck sheet varies in shapes so that it imbibes more resistance. In this paper the research is mainly focused on vibration studies of profile shapes using modal analysis. The shape involves flat plate as deck sheet, trapezoidal shape of profile, and rectangular profile with variation in height of the profile.

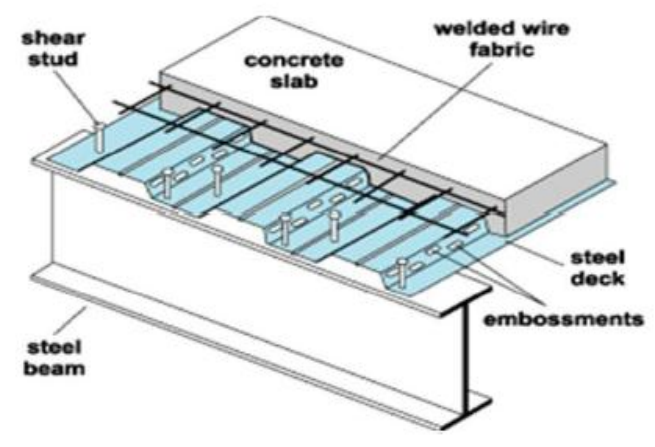

Figure:1 Composite slab with profile deck slab system

\section{PROFILED DECK SHEET}

The steel deck is normally rolled into the desired profile from $0.9 \mathrm{~mm}$ to $1.5 \mathrm{~mm}$ galvanised coil. It is profiled such that the profile heights are usually in the range of $38-75 \mathrm{~mm}$ and the pitch of corrugations is between $150 \mathrm{~mm}$ and $350 \mathrm{~mm}$. Generally, spans of the order of 2.5 $\mathrm{m}$ to $3.5 \mathrm{~m}$ between the beams are chosen and the beams are designed to span between $6 \mathrm{~m}$ to 12 $\mathrm{m}$. There are two well-known generic types of profiles.

- Dovetail profile

- Trapezoidal profile with web indentations

The common profile shapes as shown in figure: 2 compromise between enhancing the bond at the steel-concrete interface and providing stability while supporting wet concrete and other construction loads. Indentations and protrusions into the rib mobilise the bearing resistance in addition to adhesion and also provide the shear transfer in composite slabs.

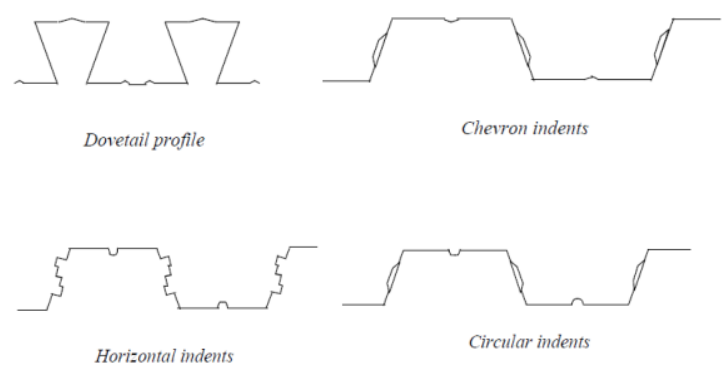

Figure: 2 Shapes of profile deck sheet

\section{STRUCTURAL DETAILS}

The profile decks considered for the modal analysis are as follows

Case I: Flat plate Deck sheet of $1 \mathrm{~mm}$ thickness

Case II: Trapezoidal shaped deck sheet 
Case III: Rectangular Shaped deck sheet

The plan dimension of the deck is $1.5 \mathrm{mx} 0.9 \mathrm{~m}$ with plate thickness of $1 \mathrm{~mm}$. The modal analysis is carried out using finite element software ANSYS19 Workbench. The finite element method is a numerical analysis technique for obtaining approximate solutions to a wide variety of engineering problems. ANSYS is a general purpose finite element modelling package for numerically solving a wide variety of problems which include static/dynamic structural analysis (both linear and nonlinear), heat transfer and fluid problems, as well as acoustic and electromagnetic problems. The present study involves following material idealisation: Steel Plate

SOLID185 is used for 3-D modelling of solid plate structures. It is defined by eight nodes having three degrees of freedom at each node: translations in the nodal $\mathrm{x}, \mathrm{y}$, and $\mathrm{z}$ directions. The element has plasticity, hyper elasti city, stress stiffening, creep, large deflection, and large strain capabilities. It also has mixed formulation capability for simulating deformations of nearly incompressible elastoplastic materials, and fully incompressible hyper elastic materials shown in Figure:3.

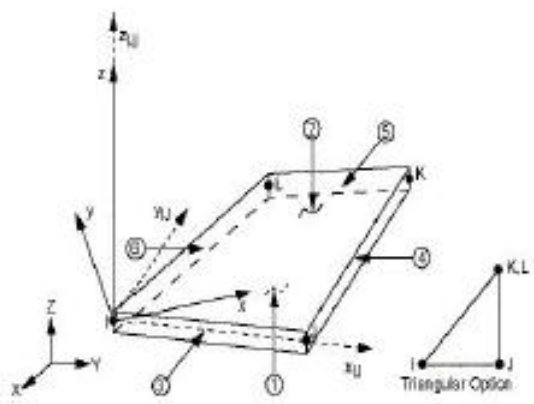

Figure:3 SOLID185 geometry

Modelling of flat plate deck as shown in figure: 4, rectangular profile deck as shown in figure:5 and trapezoidal profile deck sheet as shown in figure :6 using ANSYS 19 with same dimensions with varying profile.

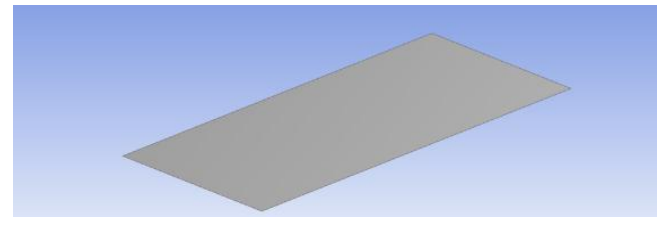

Figure: 4 Flat profile deck sheet

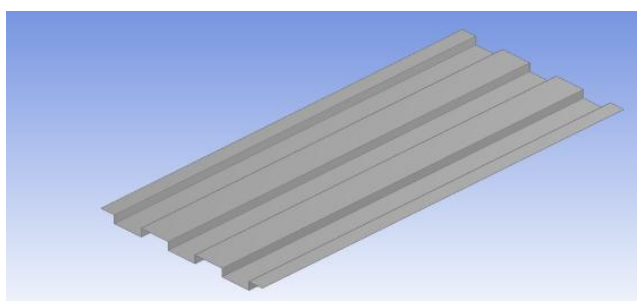

Figure: 5Rectangular profile deck sheet 


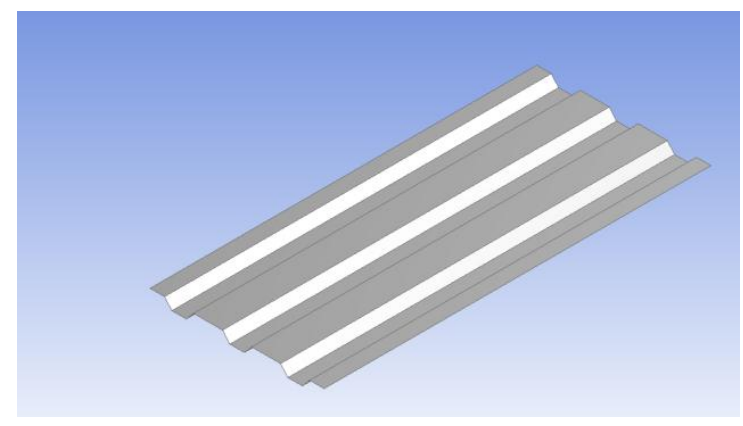

Figure: 6 Trapezoidal Profile deck sheet

The composite floor dynamic response was initially determined through an analysis of its natural frequencies and vibration modes for the three different models. The results were obtained through an extensive parametric study based on finite element simulations. The natural frequencies and vibration modes were obtained for each model as shown in figure: 7 to identify the most suitable model to represent the investigated composite floor system. The natural frequency variations for various profile shapes are tabulated as below.

Table: 1 Frequency variation based on deck sheet

\begin{tabular}{|l|l|l|l|}
\hline \multirow{2}{*}{ Mode numbers } & \multicolumn{3}{l|}{ Frequency } \\
\cline { 2 - 4 } & Flat plate & Rectangular & Trapezoidal \\
\hline 1 & 0.20923 & 15.655 & 12.195 \\
\hline 2 & 0.9881 & 17.124 & 12.603 \\
\hline 3 & 1.3097 & 25.799 & 17.414 \\
\hline 4 & 3.1836 & 47.39 & 27.111 \\
\hline 5 & 3.6796 & 76.779 & 40.759 \\
\hline 6 & 6.0076 & 85.22 & 41.117 \\
\hline 7 & 6.8253 & 89.672 & 41.172 \\
\hline 8 & 7.3793 & 95.791 & 57.899 \\
\hline 9 & 9.0192 & 116.92 & 86.757 \\
\hline 10 & 9.7664 & 132.77 & 87.133 \\
\hline
\end{tabular}

\section{FLAT PLATE DECK SHEET}

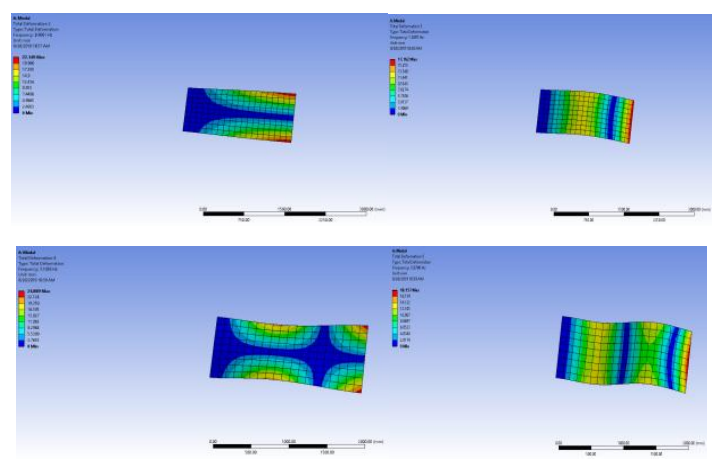


Jagadeesan R et al. / International Research Journal of Multidisciplinary Technovation /2019, 1(6), 496-502

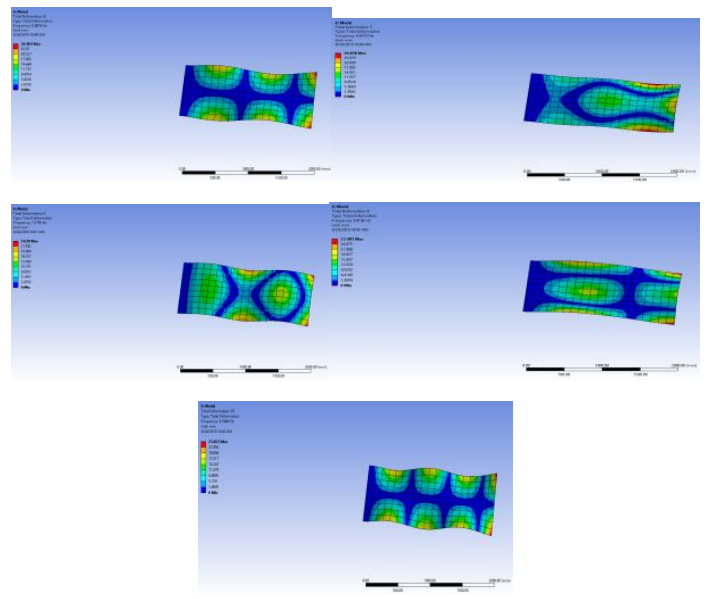

Figure: 7 Mode shape of flat plate deck sheet

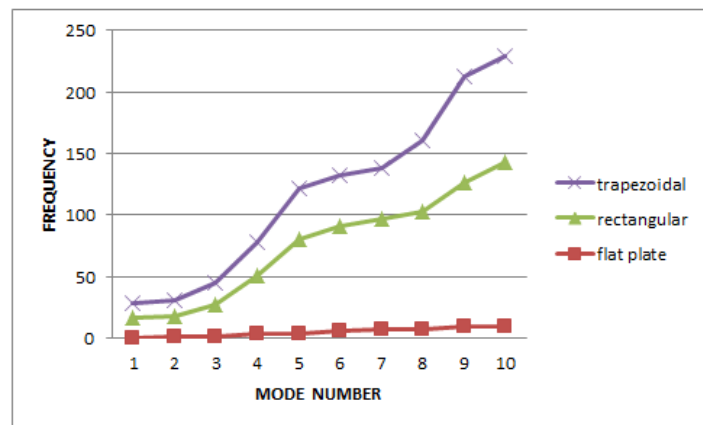

Figure:8 Variation of frequency with mode shape
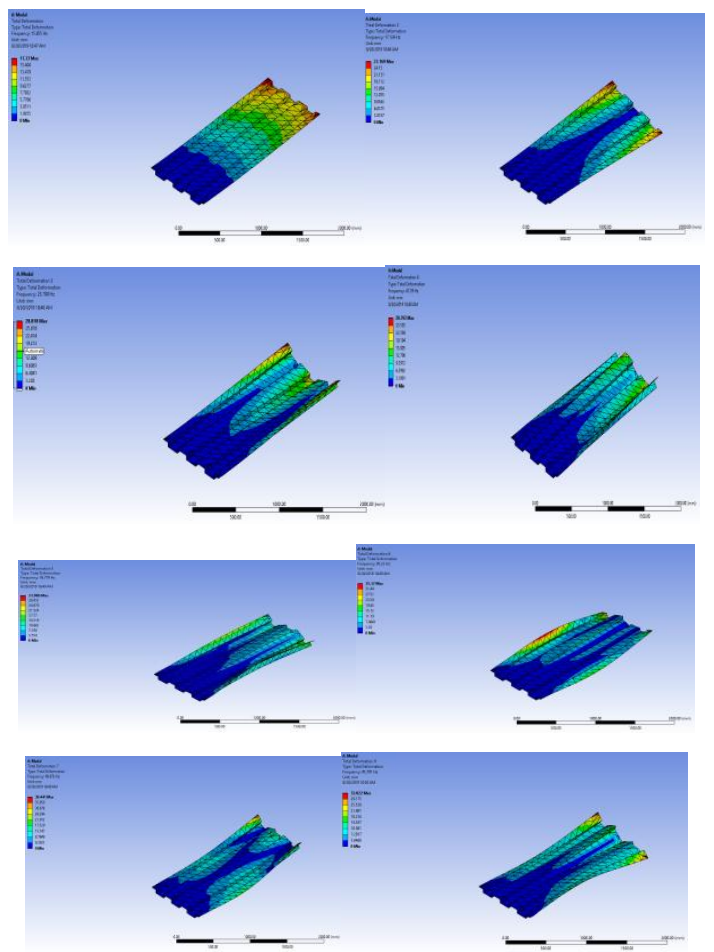


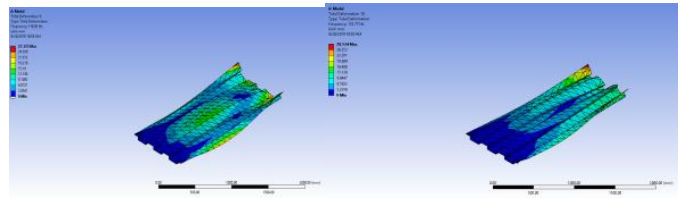

Figure: 9 Mode shape of rectangular deck sheet

\section{TRAPEZOIDAL DECK SHEET}
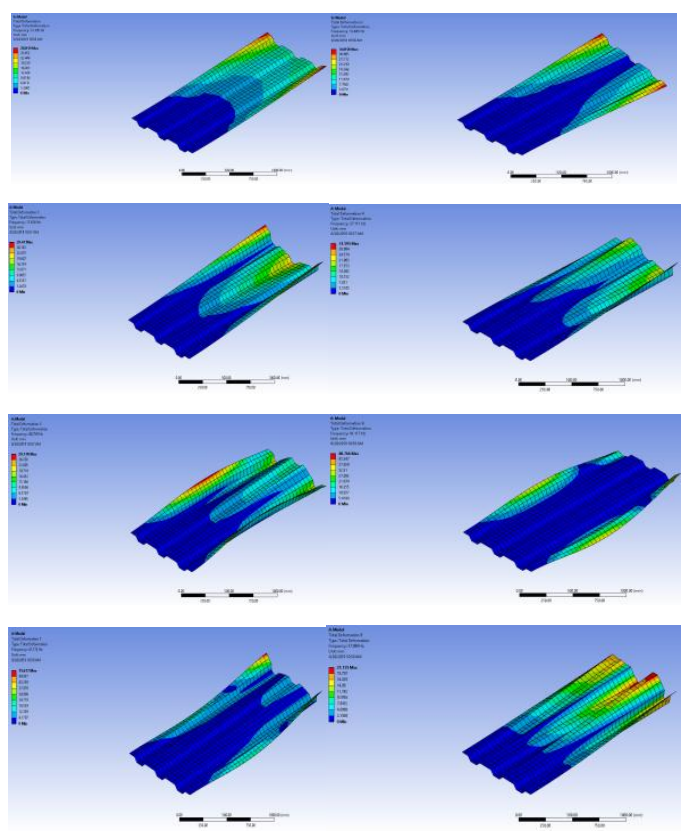

\section{CONCLUSION}

In this work, the dynamic characteristics of fixed supported deck sheets are been analysed by ANSYS19. To judge the reliability of profile deck sheets incomposite slabs, a comparison between various shapes has been made based on natural frequencies and mode shape. The variations of frequency are relatively small for rectangular and trapezoidal profile whereas, the flat plate stiffness is low when compared to other cases. The variation of ten mode shapes with its frequency values varied a lot for flat plate and other profile plates due to increase in stiffness of plate. The deformed shape of various profile deck at specific frequency shows the mode of vibration characteristic of deck sheet. The main influence of deck sheet is characterized by vibration mode shape. The vibration mode shape reflects the failure pattern and delamination behaviour of deck sheet with composite slab arrangement.

\section{REFERENCES}

1. M. S. Ahmed, F. A. Mohammad, Experimental Modal Analysis of Reinforced Concrete Square Slabs, World Academy of Science, Engineering and Technology International Journal of Civil and Environmental Engineering Vol:9, No:3, 2015.

2. BS5950 Structural use of steelwork in building.Part 4: Code of practice for design of composite slabs with profiled sheeting. 1994.

3. IS: 456:2000 Plain and reinforced concrete-code practice(2000) 
Jagadeesan R et al. / International Research Journal of Multidisciplinary Technovation /2019, 1(6), 496-502

4. A.Siva, S.Swaminathan, K.Prasanth, R.Senthil. Experimental Investigation of Trapezoidal Profile Sheeting Under Varying Shear SpansApplied Mechanics and Materials ISSN: 16627482, Vol. 845, pp 148-153, (2016)

5. Khaled M. El-Sayed1, Nader Nabih1 and Ayat M. Taha1. Flexural Behavior of Composite Slab, Article no.AIR.18847, ISSN: 2348-0394 (2015)

6. B.Moaveni, ,X.He, J.P. Conte, , and J.I.Restrepo, Damage Identification Study of a Sevenstory Full-scale Building Slice Tested on the UCSDNEES Shake Table. Structural Safety, vol. 32, Issue 5, 2010,pp. 347- 356.

7. M.R. Davoodi, M. Mahdavi, , and S. A. Mostafavian, Experimental and Analytical Determination of Dynamic Properties of a Steel Frame with Bolted Flange Joints. Proceedings of International Conference on Engineering and Information Technology "ICEIT2012", Toronto, Canada.2012.

8. S. S. Havaldar, R. S. Sharma, V. P Raghupathy, and M Adiga, Evaluation of Dynamic Parameters of Adhesively bonded Steel and Aluminium Plates. ARPN Journal of Engineering and Applied Sciences, vol. 7, Issue 6, 2012.

9. M. R. Ashory, High Quality Modal Testing Methods. A thesis submitted for the Degree of Doctor of Philosophy in Engineering, Department of Mechanical Engineering Imperial College of Science, Technology and Medicine London, UK, 1999.

10. D.J. Ewins, Modal Testing: Theory, Practice and Application. 2nd ed. Baldock, England: Research Studies Press,2001, P. 562.

11. B. J. Schwarz, and M. H. Richardson, Experimental Modal Analysis" Vibrant Technology, Inc. Jamestown, 1999.

12. R. D. Blevins, Formulas for natural frequency and mode shape. Krieger Pub. California 95327, 2001. 